\title{
ARM
}

CLIMATE RESEARCH FACILITY

\section{Aerosol Observing System HANDBOOK}

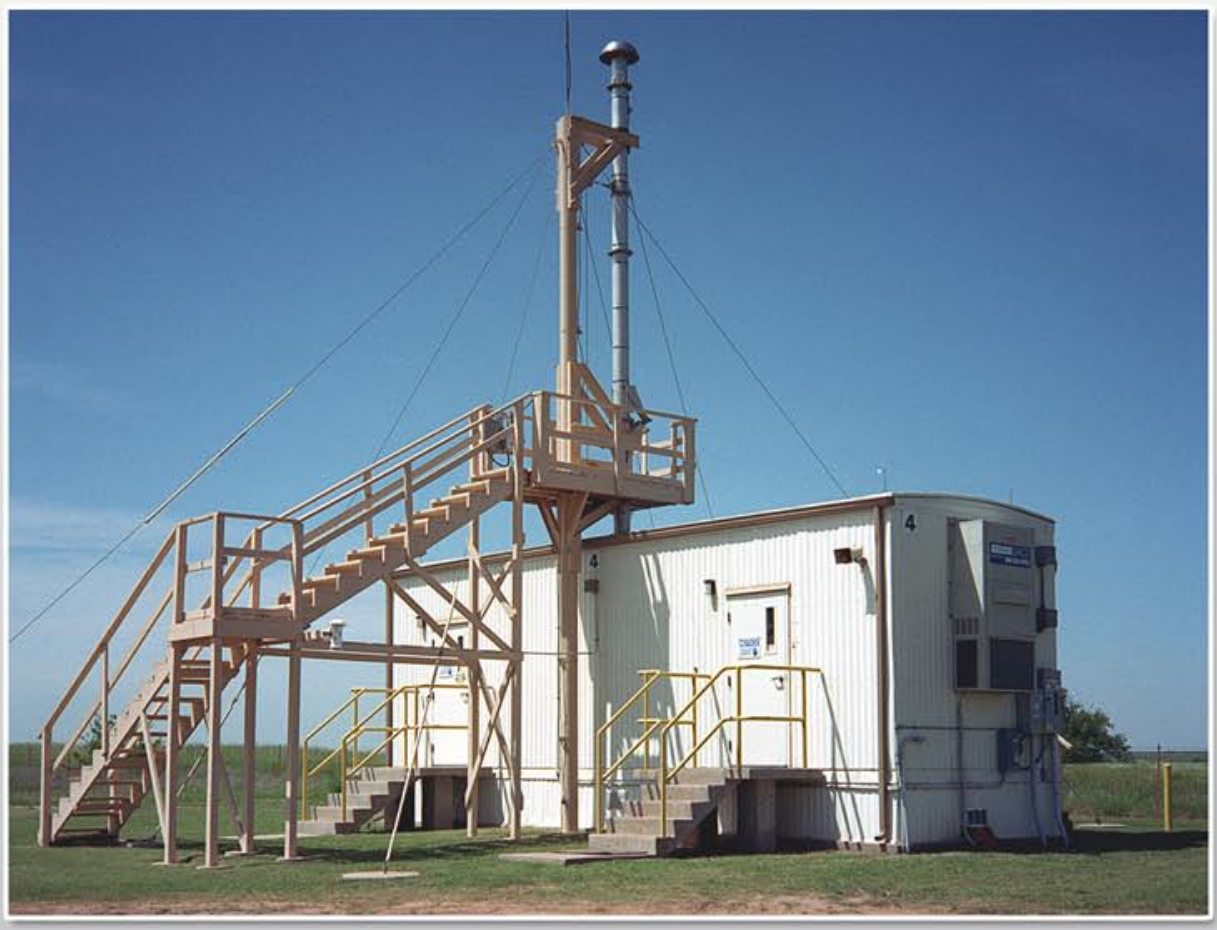

January 2011

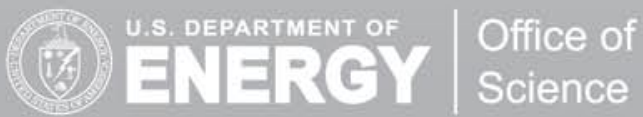




\section{DISCLAIMER}

This report was prepared as an account of work sponsored by the U.S. Government. Neither the United States nor any agency thereof, nor any of their employees, makes any warranty, express or implied, or assumes any legal liability or responsibility for the accuracy, completeness, or usefulness of any information, apparatus, product, or process disclosed, or represents that its use would not infringe privately owned rights. Reference herein to any specific commercial product, process, or service by trade name, trademark, manufacturer, or otherwise, does not necessarily constitute or imply its endorsement, recommendation, or favoring by the U.S. Government or any agency thereof. The views and opinions of authors expressed herein do not necessarily state or reflect those of the U.S. Government or any agency thereof. 


\title{
Aerosol Observing System (AOS) Handbook
}

\author{
A. Jefferson
}

January 2011

Work supported by the U.S. Department of Energy,

Office of Science, Office of Biological and Environmental Research 


\section{Contents}

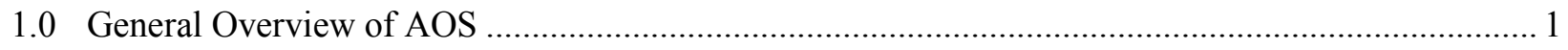

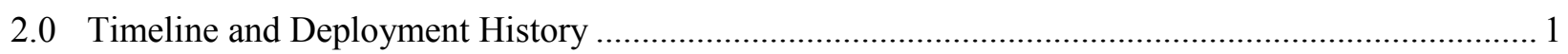

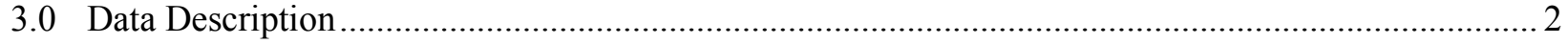

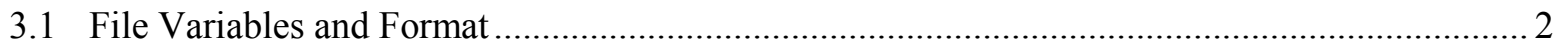

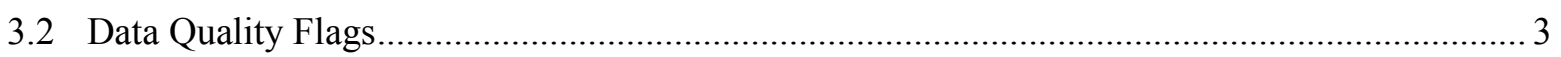

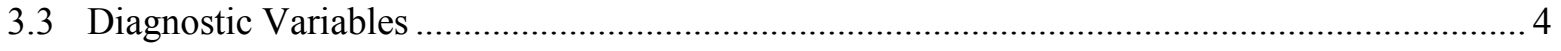

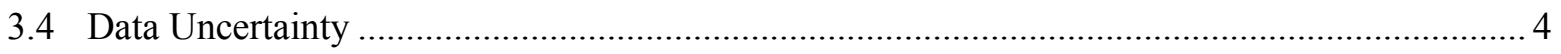

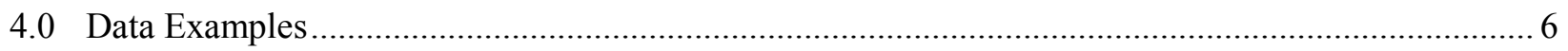

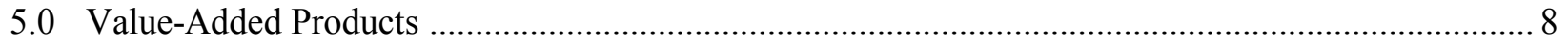

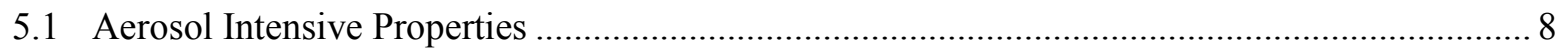

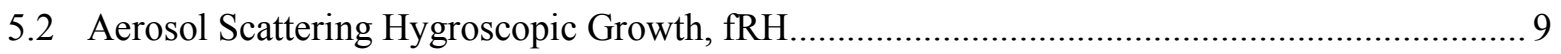

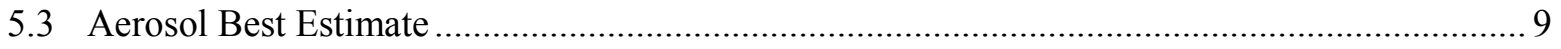

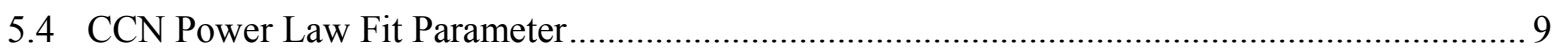

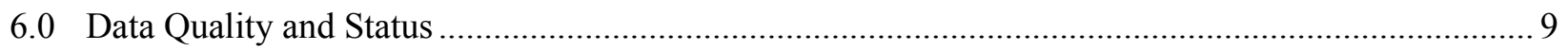

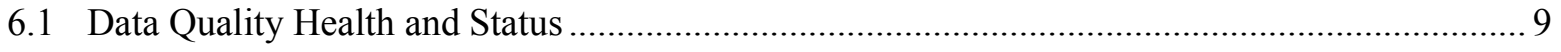

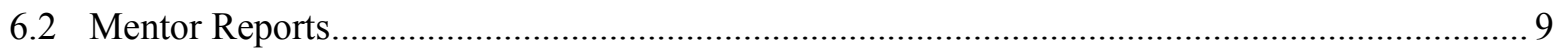

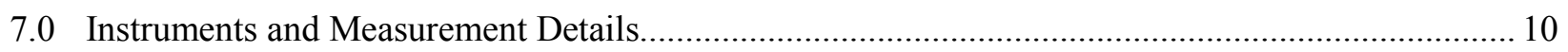

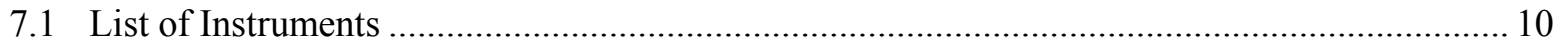

7.2 System Configuration and Measurements Methods ........................................................... 10

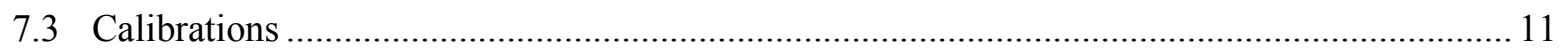

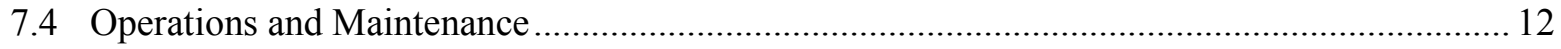

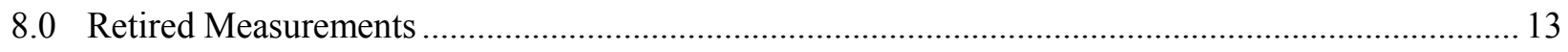

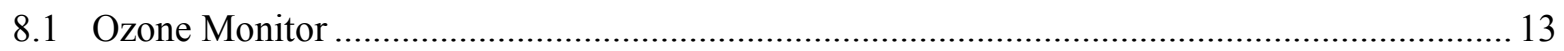

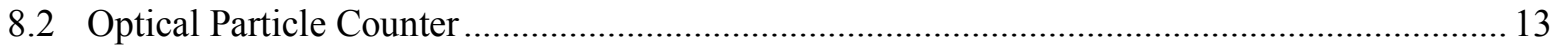

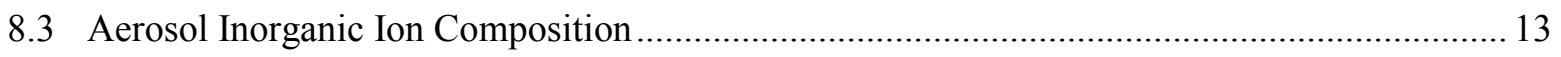

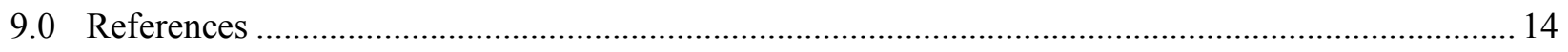

Appendix A - Aerosol Hygroscopic Growth Measurements …............................................................. A.1

Appendix B - Cloud Condensation Nuclei Measurements................................................................... 1 


\section{Figures}

1 Aerosol absorption coefficient at $550 \mathrm{~nm}$ for both submicron and sub-10-micron particle sizes.

2 Aerosol scattering coefficient at $550 \mathrm{~nm}$ for both submicron and sub-10-micron particle sizes...

3 Aerosol single scatter albedo at SGP for submicron and sub-10-micron size aerosol from November 23-29, 2010

4 Aerosol scattering Ångstrom exponent at SGP for submicron and sub-10-micron size aerosol from November 23-29, 2010.

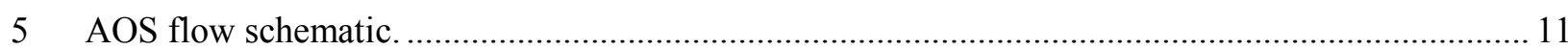

\section{Tables}

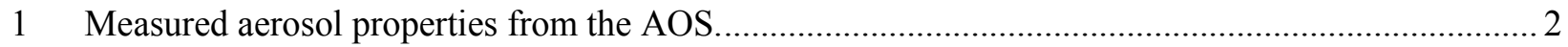

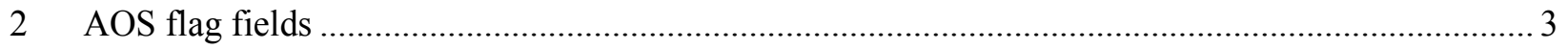

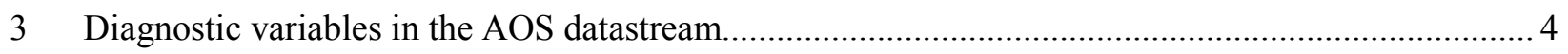

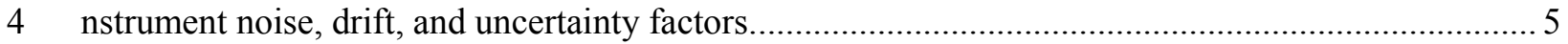




\subsection{General Overview of AOS}

The Aerosol Observing System (AOS) is a suite of in situ surface measurements of aerosol optical and cloud-forming properties. The instruments measure aerosol properties that influence the earth's radiative balance. The primary optical measurements are those of the aerosol scattering and absorption coefficients as a function of particle size and radiation wavelength and cloud condensation nuclei (CCN) measurements as a function of percent supersaturation. Additional measurements include those of the particle number concentration and scattering hygroscopic growth. Aerosol optical measurements are useful for calculating parameters used in radiative forcing calculations such as the aerosol singlescattering albedo, asymmetry parameter, mass scattering efficiency, and hygroscopic growth. CCN measurements are important in cloud microphysical models to predict droplet formation.

The system is located at the Southern Great Plains (SGP) site in Oklahoma and has been operational since the beginning of April 1996. From 1997-2010, the Aerosol Group at the National Oceanic and Atmospheric Administration's (NOAA)/Earth System Research Laboratory (ESRL)/Global Monitoring Division (GMD) had mentorship of the AOS. In March of 2005 a second AOS system was installed as part of the ARM Mobile Facility (AMF). ARM also archives AOS data from the NOAA Barrow Observatory in Barrow, Alaska at the North Slope of Alaska (NSA). Since 2011 the mentorship is a collaborative arrangement between the NOAA/ESRL/GMD group and the Cooperative Institute for Research in the Environmental Science (CIRES) at the University of Colorado.

\subsection{Timeline and Deployment History}

SGP: April 1996-present

NSA: (NOAA BRW Observatory) 1998-present

AMF:

- PYE: March-September 2005; Pt. Reyes, California, USA

- NIM: December 2005-December 2006; Niamey, Niger

- FKB: April 2007-December 2007; Heselbach, Germany

- HFE: June 2008 -December 2008; Shouxian, China

- GRW: May 2009-December 2010; Graciosa Island, the Azores, Portugal

- PGH: April 2011-March 2012; Nainital, India

Future AMF deployments and site descriptions are at http://www.arm.gov/sites/amf. 


\subsection{Data Description}

\subsection{File Variables and Format}

The current netcdf file description is located at https://engineering.arm.gov/tool/dod/showdod.php?Inst=aos\&View=user

Table 1 describes the directly measured variables from the AOS system in the stnaosC1.a1 netcdf file.

Table 1. Measured aerosol properties from the AOS.

\begin{tabular}{|c|c|c|}
\hline Variable Name & Quantity Measured & Unit \\
\hline N_CPC & Condensation nuclei number concentration & $1 / \mathrm{cm}^{3}$ \\
\hline $\mathrm{N} C \mathrm{CCN}$ & Cloud condensation nuclei number concentration & $1 / \mathrm{cm}^{3}$ \\
\hline Ba_G_Dry_loum & Aerosol absorption coefficient $550 \mathrm{~nm}, 10 \mathrm{um}$ & $1 / \mathrm{m}$ \\
\hline Ba_G Dry lum & Aerosol absorption coefficient $550 \mathrm{~nm}, 1 \mathrm{um}$ & $1 / \mathrm{m}$ \\
\hline Bs B Dry 10um & Aerosol scattering coefficient $450 \mathrm{~nm}, 10 \mathrm{um}$ & $1 / \mathrm{m}$ \\
\hline Bs B Dry lum & Aerosol scattering coefficient $450 \mathrm{~nm}, 1 \mathrm{um}$ & $1 / \mathrm{m}$ \\
\hline Bs_G_Dry_10um & Aerosol scattering coefficient $550 \mathrm{~nm}, 10 \mathrm{um}$ & $1 / \mathrm{m}$ \\
\hline Bs_G_Dry_lum & Aerosol scattering coefficient $550 \mathrm{~nm}, 1 \mathrm{um}$ & $1 / \mathrm{m}$ \\
\hline Bs_R_Dry_10um & Aerosol scattering coefficient $700 \mathrm{~nm}, 10 \mathrm{um}$ & $1 / \mathrm{m}$ \\
\hline Bs_R_Dry_lum & Aerosol scattering coefficient $700 \mathrm{~nm}, 1 \mathrm{um}$ & $1 / \mathrm{m}$ \\
\hline Bbs B Dry loum & Aerosol backscattering coefficient $450 \mathrm{~nm}, 10 \mathrm{um}$ & $1 / \mathrm{m}$ \\
\hline Bbs_B_Dry_lum & Aerosol backscattering coefficient $450 \mathrm{~nm}, 1 \mathrm{um}$ & $1 / \mathrm{m}$ \\
\hline Bbs G Dry $10 \mathrm{um}$ & Aerosol backscattering coefficient $550 \mathrm{~nm}, 10 \mathrm{um}$ & $1 / \mathrm{m}$ \\
\hline Bbs_G_Dry_lum & Aerosol backscattering coefficient $550 \mathrm{~nm}, 1 \mathrm{um}$ & $1 / \mathrm{m}$ \\
\hline Bbs_R_Dry_10um & Aerosol backscattering coefficient $700 \mathrm{~nm}, 10 \mathrm{um}$ & $1 / \mathrm{m}$ \\
\hline Bbs_R_Dry_lum & Aerosol backscattering coefficient $700 \mathrm{~nm}, 1 \mathrm{um}$ & $1 / \mathrm{m}$ \\
\hline Bs B Wet loum & Aerosol humidified scattering coefficient $450 \mathrm{~nm}, 10 \mathrm{um}$ & $1 / \mathrm{m}$ \\
\hline Bs B Wet lum & Aerosol humidified scattering coefficient $450 \mathrm{~nm}, 1 \mathrm{um}$ & $1 / \mathrm{m}$ \\
\hline Bs G Wet 10um & Aerosol humidified scattering coefficient $550 \mathrm{~nm}, 10 \mathrm{um}$ & $1 / \mathrm{m}$ \\
\hline Bs_G Wet lum & Aerosol humidified scattering coefficient $550 \mathrm{~nm}, 1 \mathrm{um}$ & $1 / \mathrm{m}$ \\
\hline Bs R Wet 10um & Aerosol humidified scattering coefficient $700 \mathrm{~nm}, 10 \mathrm{um}$ & $1 / \mathrm{m}$ \\
\hline Bs_R_Wet_lum & Aerosol humidified scattering coefficient $700 \mathrm{~nm}, 1 \mathrm{um}$ & $1 / \mathrm{m}$ \\
\hline Bbs_B Wet $10 \mathrm{um}$ & Aerosol humidified backscattering coefficient $450 \mathrm{~nm}, 10 \mathrm{um}$ & $1 / \mathrm{m}$ \\
\hline Bbs B Wet lum & Aerosol humidified backscattering coefficient $450 \mathrm{~nm}, 1 \mathrm{um}$ & $1 / \mathrm{m}$ \\
\hline Bbs G Wet 10um & Aerosol humidified backscattering coefficient $550 \mathrm{~nm}, 10 \mathrm{um}$ & $1 / \mathrm{m}$ \\
\hline Bbs_G_Wet_lum & Aerosol humidified backscattering coefficient $550 \mathrm{~nm}, 1 \mathrm{um}$ & $1 / \mathrm{m}$ \\
\hline Bbs_R_Wet_10um & Aerosol humidified backscattering coefficient $700 \mathrm{~nm}, 10 \mathrm{um}$ & $1 / \mathrm{m}$ \\
\hline Bbs_R_Wet_lum & Aerosol humidified backscattering coefficient $700 \mathrm{~nm}, 1 \mathrm{um}$ & $1 / \mathrm{m}$ \\
\hline Ba_B_Dry_10um_PSAP3W & Aerosol absorption coefficient $467 \mathrm{~nm}, 10 \mathrm{um}$ & $1 / \mathrm{m}$ \\
\hline Ba B Dry 10um PSAP3W & Aerosol absorption coefficient $467 \mathrm{~nm}, 1 \mathrm{um}$ & $1 / \mathrm{m}$ \\
\hline Ba B Dry 10um PSAP3W & Aerosol absorption coefficient $530 \mathrm{~nm}, 10 \mathrm{um}$ & $1 / \mathrm{m}$ \\
\hline Ba_B Dry 10um PSAP3W & Aerosol absorption coefficient $530 \mathrm{~nm}, 1 \mathrm{um}$ & $1 / \mathrm{m}$ \\
\hline Ba_B_Dry_10um_PSAP3W & Aerosol absorption coefficient $660 \mathrm{~nm}, 10 \mathrm{um}$ & $1 / \mathrm{m}$ \\
\hline Ba_B_Dry_10um_PSAP3W & Aerosol absorption coefficient $660 \mathrm{~nm}, 1 \mathrm{um}$ & $1 / \mathrm{m}$ \\
\hline
\end{tabular}




\subsection{Data Quality Flags}

A data flag designates the sampling conditions and level of data processing. The flag field is in hexadecimal format. Of particular importance is the third character bit, which designates the aerosol impactor sampling size. The aerosol sampling switches every 30 minutes between sub-10-micron (0000) and submicron (0010) size aerosol. Table 2 lists the flags and their designations.

Table 2. AOS flag fields

\begin{tabular}{|c|c|c|c|c|}
\hline Bit Position & $\begin{array}{l}\text { Hex Bit } \\
\text { Mask }\end{array}$ & Description & Bit Set (1) & Bit Clear (0) \\
\hline \multicolumn{5}{|l|}{1} \\
\hline $1: 3$ & 8000 & Not used & & \\
\hline $1: 2$ & 4000 & Not used & & \\
\hline $1: 1$ & 2000 & Not used & & \\
\hline $1: 0$ & 1000 & Not used & & \\
\hline 2 & & Data Corrections & & \\
\hline $2: 3$ & 0800 & Dilution & Applied & Not applied \\
\hline $2: 2$ & 0400 & Neph truncation & Applied & Not applied \\
\hline $2: 1$ & 0200 & $\begin{array}{l}\text { Psap spot and } \\
\text { flow corrections }\end{array}$ & Applied & Not applied \\
\hline $2: 0$ & 0100 & STP & Applied & Not applied \\
\hline 3 & & $\begin{array}{l}\text { Sampling } \\
\text { Conditions }\end{array}$ & & \\
\hline $3: 3$ & 0080 & Not used & & \\
\hline $3: 2$ & 0040 & Not used & & \\
\hline $3: 1$ & 0020 & $\begin{array}{l}\text { Psap } \\
\text { transmission }(\mathrm{Tr})\end{array}$ & $\operatorname{Tr}<0.7$ & $\operatorname{Tr}>0.7$ \\
\hline $3: 0$ & 0010 & Impactor size & submicron & Sub 10 micron \\
\hline 4 & & $\begin{array}{l}\text { Sampling } \\
\text { Conditions }\end{array}$ & & \\
\hline $4: 3$ & 0008 & Not used & & \\
\hline $4: 2$ & 0004 & Wind Sector & Pollution & Clean \\
\hline $4: 1$ & 0002 & $\begin{array}{l}\text { Manual contamination } \\
\text { control }\end{array}$ & Pollution & Clean \\
\hline $4: 0$ & 0001 & $\begin{array}{l}\text { Automatic } \\
\text { contamination control }\end{array}$ & Pollution & Clean \\
\hline
\end{tabular}




\subsection{Diagnostic Variables}

The diagnostic variables in the AOS datastream include those of the instrument temperature, pressure, $\mathrm{RH}$, wind speed, and direction. A description of each parameter is given in Table 3. The ambient variables as well as wind speed and direction are not merged in all of the AOS datastreams.

Table 3. Diagnostic variables in the AOS datastream.

\begin{tabular}{|l|l|l|}
\hline Variable name & Description & Unit \\
\hline RH_MainInlet & RH at impactor inlet & $\%$ \\
\hline T MainInlet & Temperature at impactor inlet & ${ }^{\circ} \mathrm{C}$ \\
\hline RH_NephInlet_Dry & RH at dry nephelometer inlet & $\%$ \\
\hline T_NephInlet_Dry & $\begin{array}{l}\text { Temperature at dry nephelometer } \\
\text { inlet }\end{array}$ & ${ }^{\circ} \mathrm{C}$ \\
\hline RH_NephVol_Dry & RH inside the dry nephelometer & $\%$ \\
\hline T_NephVol_Dry & $\begin{array}{l}\text { Temperature inside the dry } \\
\text { nephelometer }\end{array}$ & ${ }^{\circ} \mathrm{C}$ \\
\hline RH_preHG & RH before the humidifier & $\%$ \\
\hline T_preHG & Temperature before the humidifier & ${ }^{\circ} \mathrm{C}$ \\
\hline RH_postHG & RH after the humidifier & $\%$ \\
\hline T_postHG & Temperature after the humidifier & ${ }^{\circ} \mathrm{C}$ \\
\hline RH NephInlet Wet & RH at inlet of wet nephelometer & $\%$ \\
\hline T_NephInlet_Wet & $\begin{array}{l}\text { Temperature at inlet of wet } \\
\text { nephelometer }\end{array}$ & ${ }^{\circ} \mathrm{C}$ \\
\hline RH NephVol Wet & RH inside wet nephelometer & $\%$ \\
\hline T_NephVol_Wet & $\begin{array}{l}\text { Temperature inside wet } \\
\text { nephelometer }\end{array}$ & ${ }^{\circ} \mathrm{C}$ \\
\hline RH_ambient & Ambient RH & $\%$ \\
\hline T ambient & Ambient temperature & $\mathrm{O}$ \\
\hline P_ambient & Ambient pressure & $\mathrm{h}$ \\
\hline P Neph_Dry & Pressure inside dry nephelometer & $\mathrm{hPa}$ \\
\hline P Neph Wet & Pressure inside wet nephelometer & $\mathrm{hPa}$ \\
\hline WindSpeed & Wind Speed & $\mathrm{m} / \mathrm{s}$ \\
\hline WindDirection & Wind Direction & $\mathrm{degrees}$ \\
\hline Lat & Latitude & $\mathrm{degrees}$ \\
\hline Lon & Longitude & $\mathrm{Degrees}$ \\
\hline Alt & Altitude & \\
\hline
\end{tabular}

\subsection{Data Uncertainty}

The calculation of the measurement uncertainty of each nephelometer follows the protocol of Anderson et al. (1999). The measurement uncertainty associated with the TSI 3563 nephelometer was calculated from five known sources and is expressed as a linear combination of the following terms:

$\mathrm{du}_{\text {total }}^{2}=\mathrm{du}_{\text {noise }}{ }^{2}+\mathrm{du}_{\mathrm{drift}^{2}}^{2}+\mathrm{du}_{\mathrm{cal}}^{2}+\mathrm{du}_{\text {trunc }}{ }^{2}+\mathrm{du}_{\mathrm{stp}}^{2}$. 
Here, dup designates the uncertainty in $u$ associated with the parameter, $p$. These arise from the following:

- instrument noise in the filtered air scattering coefficient

- instrument drift in the calibration

- uncertainty in the instrument calibration to Rayleigh scattering of dry air and $\mathrm{CO}_{2}$

- instrument truncation of near forward scattered light

- uncertainty in the instrument pressure and temperature in conversion of the data to STP.

The associated uncertainties for each parameter for one-minute averages are listed in Table 4 as a function of the scattering coefficient magnitude.

Table 4. Instrument noise, drift, and uncertainty factors.

\begin{tabular}{|l|l|l|l|l|l|l|}
\hline Bsp & Noise & Drift & Calibration & Truncation & STP & Total \\
\hline 1 & 1.25 & 0.44 & 0.08 & 0.02 & 0.003 & $\mathbf{1 . 3 3}$ \\
\hline 10 & 1.56 & 0.80 & 0.75 & 0.22 & 0.03 & $\mathbf{1 . 9 2}$ \\
\hline 20 & 1.84 & 1.20 & 1.50 & 0.44 & 0.07 & $\mathbf{1 . 7 0}$ \\
\hline 50 & 2.50 & 2.40 & 3.75 & 1.10 & 0.17 & $\mathbf{5 . 2 3}$ \\
\hline 100 & 3.32 & 4.40 & 7.51 & 2.10 & 0.34 & $\mathbf{9 . 5 8}$ \\
\hline
\end{tabular}

Uncertainty associated with differences in the aerosol inlets and tubing is expected to be insignificant for submicron aerosol. Losses within the nephelometer itself were found to be negligible for submicron particles and are 5\%-10\% for super micrometer particles (Anderson and Ogren 1998). The variation in particle size with relative humidity $(\mathrm{RH})$ and hence, the particle transmission through a submicron impactor, operating upstream of the nephelometer, will vary with the particle type. For an RH below $50 \%$, we estimate this uncertainty to be less than 5\% based on Berner impactor efficiency curves and estimates of the scattering size distribution. In addition to $\mathrm{RH}$, the flow rate affects the $50 \%$ aerodynamic cutoff diameter of the impactor. Running the Berner-type impactors at a flow 10\% lower than $30 \mathrm{lpm}$ yields a $5 \%$ change in cut size. Typically, flows are within $1 \%-2 \%$ of the expected flow rate.

For low-scattering values, instrument noise is the prevalent source of uncertainty, while for higher scattering coefficients both noise and instrument truncation uncertainties dominate. Uncertainty for low signal values can be greatly reduced by increasing the signal averaging time. For a 10-min averaging time, the uncertainty associated with noise for a bsp of $1 \mathrm{Mm}^{-1}$ is $0.40 \mathrm{Mm}^{-1}$. Truncation corrections for sub-10 $u \mathrm{~m}$ and super- $u \mathrm{~m}$ size particles are significantly higher than those for sub- $u \mathrm{~m}$ size particles. See Anderson and Ogren 1998 and Heintzenburg et al. 2006 for discussions on the uncertainty of nephelometer scattering coefficients.

Uncertainty in the particle soot absorption photometer (PSAP) has been described by Sheridan et al. (2005) and Virkkula et al. (2010). Corrections have been made for spot size, flow rate, wavelength, interpretation of scattering as absorption, and instrument response to absorption (Bond et al. 2001 and Ogren 2010). Uncertainty in the measurements also stems from the variability of each PSAP unit and from instrument noise. Bond et al. found instrumental variability to be $6 \%$ of the measured absorption. Instrument noise (i.e. detection limit), determined by measuring particle-free air, is $0.1 \mathrm{Mm}^{-1}$ for hourly 
averaged data and $0.9 \mathrm{Mm}^{-1}$ for minute-averaged data. The total uncertainty in aerosol absorption coefficient from the PSAP usually varies from 1 to $4 \mathrm{Mm}^{-1}$ for one-minute average data and depends on the magnitudes of the absorption and scattering coefficients. PSAP noise and uncertainty was found to increase in high RH environments and in air with high concentrations of semi-volatile organics (Lack et al. 2008).

\subsection{Data Examples}

The data in Figures 1 and 2 show typical aerosol absorption and scattering coefficients at $550 \mathrm{~nm}$ for both aerosol size cuts. The data are from November 23-29, 2010 at SGP with one-minute integration times. The two colors indicate the two aerosol sizes, which change every 30 minutes. On day 328, November 24 , larger supermicron aerosol are present, and the scattering between the two size cuts diverge. Because most of the absorbing aerosol resides in the submicron size range, there is little difference between the submicron and sub-10-micron absorption coefficients on this day. Figures 3 and 4 show the changes in the aerosol size and absorption properties during the same time period.

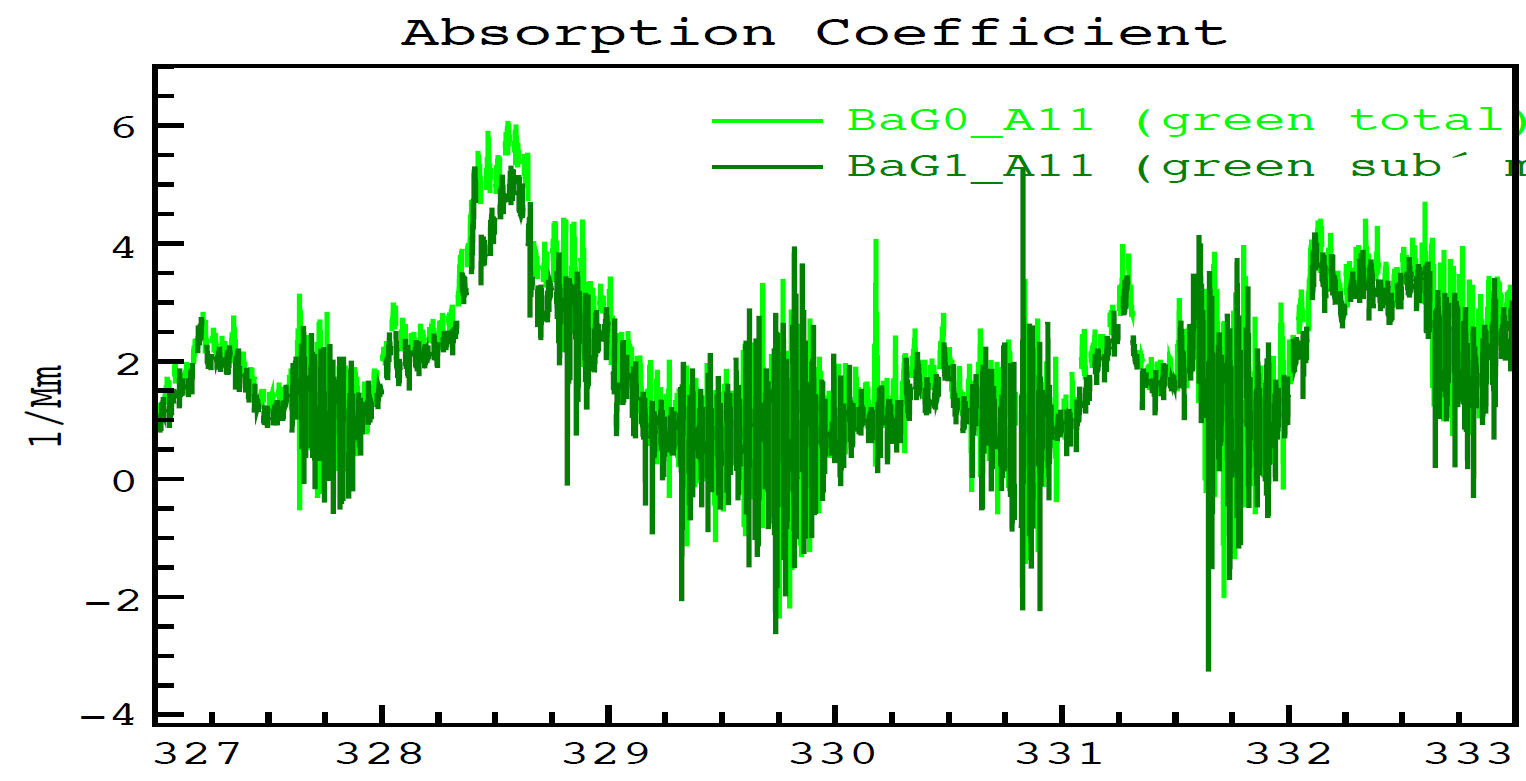

Figure 1. Aerosol absorption coefficient at $550 \mathrm{~nm}$ for both submicron and sub-10-micron particle sizes. 


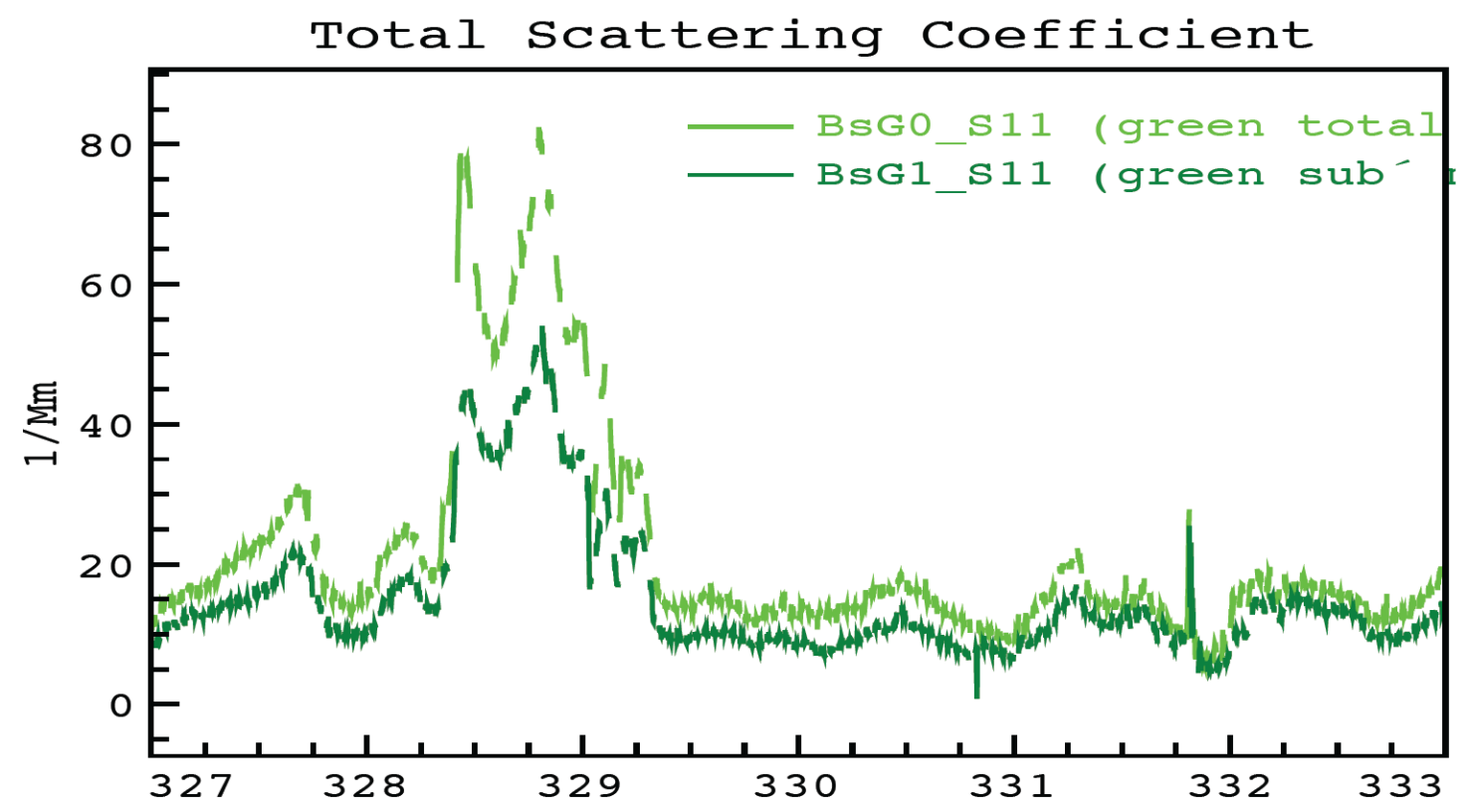

Figure 2. Aerosol scattering coefficient at $550 \mathrm{~nm}$ for both submicron and sub-10-micron particle sizes.

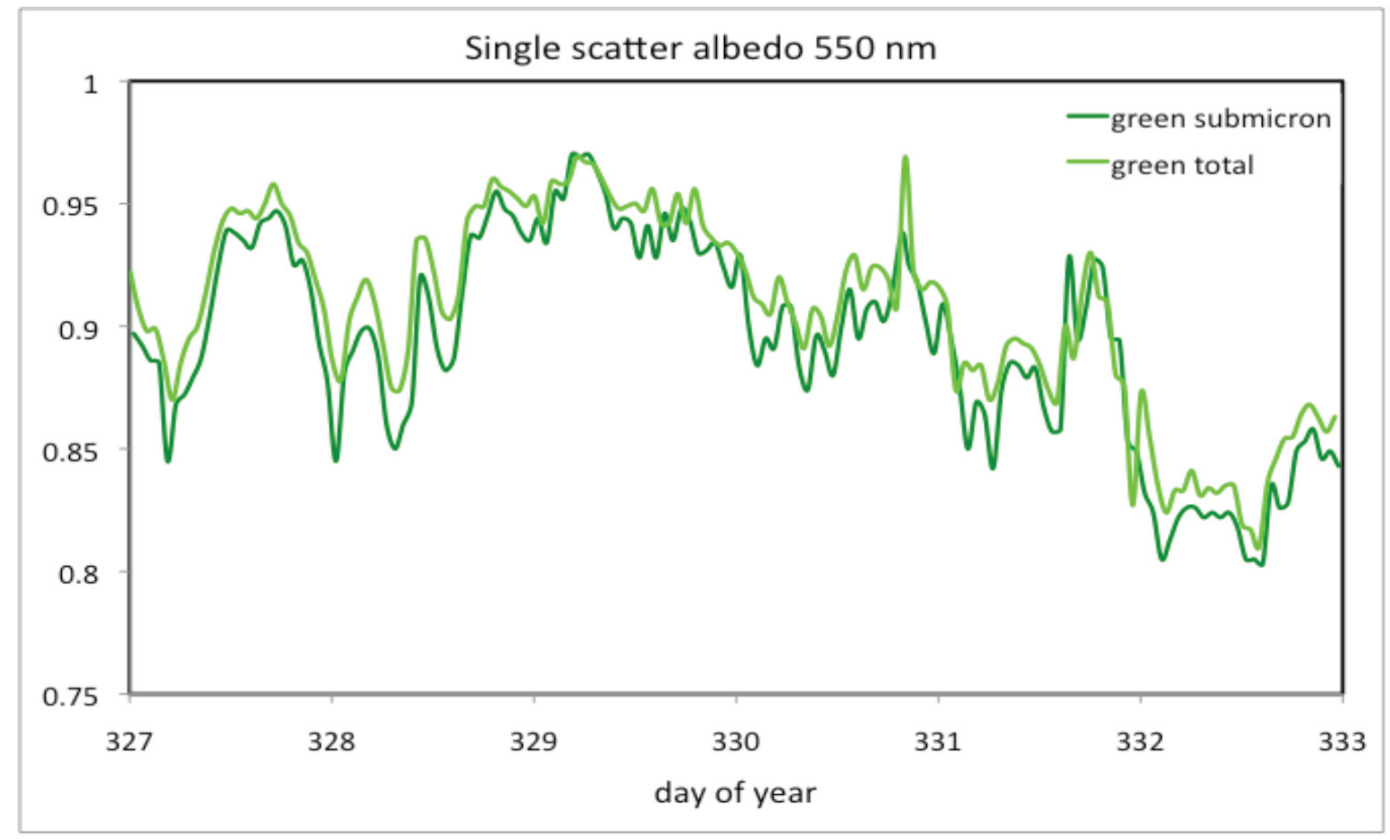

Figure 3. Aerosol single scatter albedo at SGP for submicron and sub-10-micron size aerosol from November 23-29, 2010. 


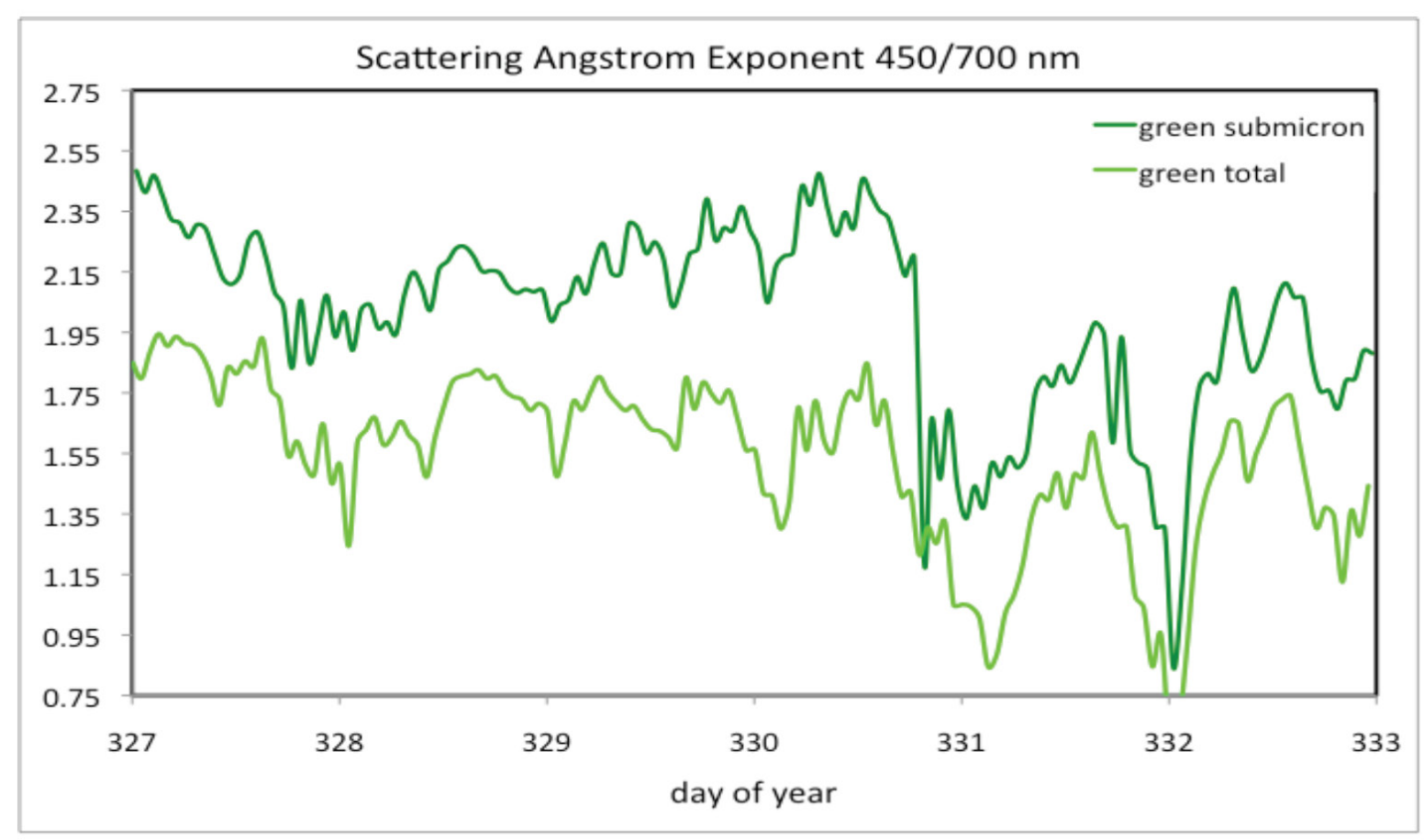

Figure 4. Aerosol scattering Ångstrom exponent at SGP for submicron and sub-10-micron size aerosol from November 23-29, 2010.

Figures 3 and 4 display the aerosol scattering albedo and Angstrom exponents over the same time period as the data in Figures 1 and 2. The data in the figures are 30-minute averages. The relatively large separation in the Angstrom exponents between the two size cuts suggests a significant fraction of coarsemode aerosol was present. Differences between the aerosol scattering albedo in the two size cuts are small, with the total sub-10-micron aerosol having a slightly higher albedo than the submicron aerosol.

\subsection{Value-Added Products (VAPs)}

\subsection{Aerosol Intensive Properties}

The aerosol intensive properties are calculated properties from the measured extensive parameters. The intensive parameters calculated from the aerosol absorption, scattering, and backscattering coefficients are the single scatter albedo, hemispheric backscatter fraction, upscatter fraction, asymmetry parameter, submicron absorption fraction, submicron scattering fraction, aerosol forcing efficiency, and the absorption and scattering Ångstrom exponents. The intensive properties are located in two files: sssaipogrenFn.c1 and ssaaipavglogrenFn.c1. The sss prefix designates the site location and Fn the facility at the site. The aiplogren files are one-minute averaged data, and the aipavglogren files are hourly averaged data. An extensive description of the file format, variable description, and calculation process is located on the ARM website at http://science.arm.gov/vaps/aiplogren.stm. 


\subsection{Aerosol Scattering Hygroscopic Growth, fRH}

The aerosol hygroscopic growth is a measure of the increase in the aerosol scattering coefficient with relative humidity. A description of the humidified measurements and hygroscopic growth calculations is located in Appendix A. As of 2011 the hygroscopic growth VAP was still in its evaluation period and had not been released. Please contact the mentor for information on this VAP.

\subsection{Aerosol Best Estimate}

The Aerosol Best Estimate (ABE) product gives profiles of the aerosol intensive properties as a function of altitude. AOS and aipogren VAP data contribute to the ABE product. As of 2011 this product was still in its evaluation period.

\subsection{CCN Power Law Fit Parameter}

This product has yet to be evaluated. More information on it is available in Appendix B, which describes the $\mathrm{CCN}$ measurements and data.

\subsection{Data Quality and Status}

\subsection{Data Quality Health and Status}

An interactive plotting tool is available on the ARM Data Management Facility website, where users can plot recent or past AOS data from the various sites. The data-plotting tool is available at http://plot.dmf.arm.gov/ncvweb/ncvweb.cgi . The tool plots raw data from the most recent quarter. Recent and statistical plots of the AOS data are also available on the NOAA/ESRL/GMD website at http://www.esrl.noaa.gov/gmd/aero/net/index.html.

\subsection{Mentor Reports}

Data quality reports (DQRs) and Instrument Mentor Monthly Summaries (IMMS) are available from the ARM database at http://www.db.arm.gov/. The IMMS reports provide a monthly summary of both the data and the instrument operation. The DQRs identify problems with the data. Both report types should be checked prior to using AOS data. 


\subsection{Instruments and Measurement Details}

\subsection{List of Instruments}

Aerosol instrumentation inside the trailer consists of the following:

1. Two nephelometers. These are 3-wavelength (450, 550, and $700 \mathrm{~nm}$ ) TSI (Model 3563) nephelometers that measure total angular scattering and hemispheric backscattering coefficients from $90^{\circ}$ to $170^{\circ}$. The second TSI nephelometer is connected to a humidity scanning system to provide 12 measurements of the scattering coefficients as a function of RH. A check of the nephelometer calibration with $\mathrm{CO}^{2}$ gas is performed weekly.

2. Light absorption photometer. The Radiance Research (Model PSAP) Particle Soot Absorption Photometer measures the particle absorption coefficient at the wavelength of $550 \mathrm{~nm}$. In April 2005, this instrument was upgraded to a 3-wavelength instrument (470, 528, and $660 \mathrm{~nm})$.

3. Condensation nuclei counter. The TSI (Model 3010) measures the total number concentration of condensation particles of diameter in the size range of $10 \mathrm{~nm}$ to $3 \mu \mathrm{m}$.

4. Cloud Condensation Nuclei Counter (CCN), single-column DMT Model 1. The CCN measures the cloud droplet concentration at 7 supersaturations as well as the droplet size distribution from $1 \mathrm{um}$ to $10 \mathrm{um}$ in 20 size bins.

5. Continuous Light Absorption Photometer (CLAP), NOAA. The CLAP is a filter-based technique that measures the aerosol light absorption coefficient at three visible wavelengths, 470, 528, and 660 $\mathrm{nm}$.

\subsection{System Configuration and Measurements Methods}

Figure 5 below shows the AOS flow schematic. About $800 \mathrm{lpm}$ flow through an 8 " diameter external stack. The sample air flows through a 2" diameter stainless steel pipe in the center of this larger flow. $120 \mathrm{lpm}$ flows through the sample tube, which splits into five 30-lpm sample lines. At the AMF one of these sample lines goes into the AOS system, and the other 4 spare sample lines go out through a blower. At SGP the spare sample lines go to the HTDMA, ACSM, and PAAS instruments, and one line is used to monitor the temperature and $\mathrm{RH}$ at the exit of the sample flow splitter.

The nephelometer and PSAP instruments are downstream of a set of switched impactors. These impactors toggle the aerosol size cut between $1.0 \mathrm{um}$ and $10 \mathrm{um}$ aerodynamic particle diameters every 30 minutes. The advantage of measuring two aerosol size ranges is that fine and coarse mode aerosols often have different sources, and this method allows optical measurements of both aerosol types. 


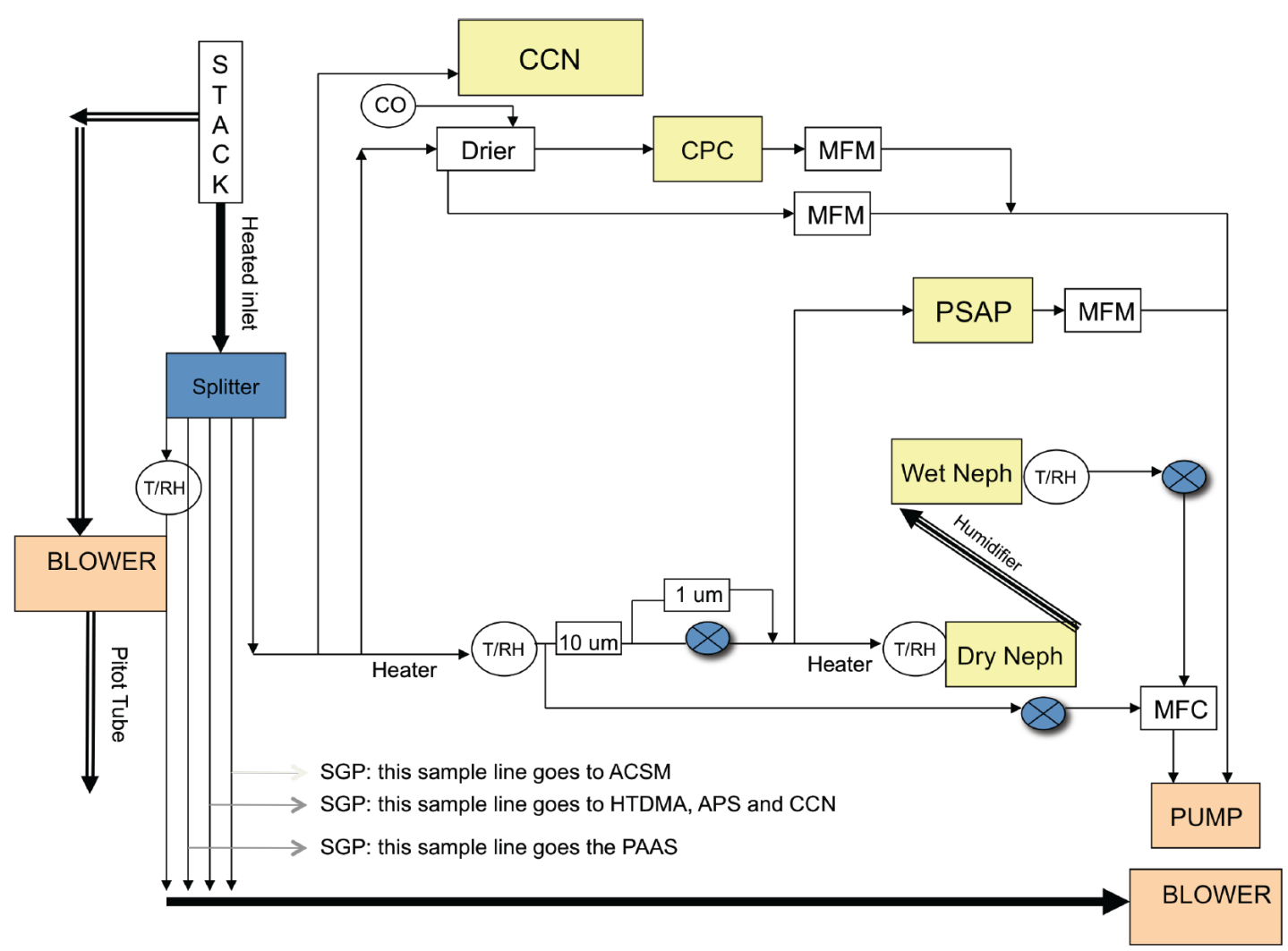

Figure 5. AOS flow schematic. Symbols represent the following: T/RH: temperature and relative humidity sensor; CO: critical orifice; MFM: mass flow meter; and MFC: mass flow controller. Blue Xs are valves.

The relative humidities of the four T/RH sensors shown in Figure 5 are regulated via PID (proportional, differential, and integrative) controllers. These PID controllers regulate the relative humidity at the output of the sample splitter and immediately upstream of the impactors to $40 \% \mathrm{RH}$. An RH of $40 \%$ was chosen to measure the properties of the intrinsic "dry" aerosol with minimal contribution from water and also to minimize evaporation of semi-volatile organics and acids from the aerosol. The RH immediately upstream of the reference or dry nephelometer and humidifier is controlled to $40 \%$, and the $\mathrm{RH}$ after the wet nephelometer and humidifier is ramped hourly between about 40 to $85 \% \mathrm{RH}$. See Appendix A for information about the humidifier operation.

\subsection{Calibrations}

The instrument flow, pressure, temperature, and relative humidity sensors are calibrated annually. A Bios-brand flow standard is used to calibrate the instrument flows. The SGP facility maintains a Thunder Scientific RH and temperature calibration chamber that is traceable to NIST standards. The SGP and AMF Vaisala $\mathrm{T} / \mathrm{RH}$ probes are calibrated in this chamber. A magnehelic gauge is used to calibrate the pressure sensors. 


\subsection{Operations and Maintenance}

\section{Daily Maintenance}

- Check flows and vacuum readings

- Check instrument and computer communications

- Change PSAP and CLAP filter as needed

- Fill humidifier and CCN water supplies

- Fill CPC butanol as needed.

\section{Weekly Maintenance}

- $\mathrm{CO}^{2}$ span check of nephelometers

- Clean impactors

- Change PSAP reference filter.

\section{Periodic Maintenance}

- Leak check of system

- Change neph lamp

- Clean CPC

- Drain and refill butanol in CPC.

\section{Annual Maintenance}

- Perform flow calibrations on main sample flow, cpc critical orifice, PSAP, and CCN sheath and sample flows

- Calibrate CCN pressure, impactor delta $\mathrm{P}$, and blower pitot

- Clean CPC

- Replace CCN, mass flow meter, and neph hepa filters

- Clean CCN opc

- Bleach solution purge of CCN column

- Clean capillary sample tube in CCN

- Replace CCN pump diaphragm

- Leak check of CCN

- Remove files from $\mathrm{CCN}$ hard drive

- Clean inlet lines

- System leak check 
- Update software

- Clean nephelometers

- Calibrate nephelometers

- Replace carbon vanes in pump

- Replace cracked or dirty tubing

- Clean or replace humidifier

- Replace nafion tubes before CPC and PSAP and in CCN

- Train site technician

- Perform inventory of AOS parts and spares.

\subsection{Retired Measurements}

\subsection{Ozone Monitor}

The Dasibi (Model 1008) ozone monitor measures the ozone mixing ratio between 1 and $1000 \mathrm{ppbv}$ using monochromatic ultraviolet (UV) absorption spectrophotometry. This instrument was in operation at SGP from 1998-2004.

\subsection{Optical Particle Counter}

The PMS (Model PCASP-X) OPC measures the particle number concentration in 31 size channels from 0.1 to $10 \mu \mathrm{m}$. This instrument was inoperable and removed in 2004 because of poor instrument reliability. The data collection for this instrument spanned from 1997-2004. In 2008 a TSI model 3321 Aerodynamic Particle Sizer (APS) was installed as a complement to the HTDMA. The size range of the APS is 0.5 to $20 \mathrm{um}$.

\subsection{Aerosol Inorganic Ion Composition}

Daily filter samples of aerosol were collected as SGP from 2000-2008. Patricia Quinn of NOAA PMEL analyzed the daily samples for the aerosol inorganic ion composition. Similar filter samples are collected at the NSA Barrow site that date from 1998 to the present. The sample duration at NSA varies from daily in the spring when aerosol loading is relatively high to one sample per week in the summer and fall when aerosol loading is low. Data from these filter samples are located on the PMEL web site at http://saga.pmel.noaa.gov/. 


\subsection{References}

Anderson, TL, and JA Ogren. 1998. "Determining aerosol radiative properties using the TSI 3563 integrating nephelometer." Aerosol Science and Technology 29: 57-69.

Anderson, TL, DS Covert, JD Wheeler, JM Harris, KD Perry, BE Trost, DJ Jaffe, and JA Ogren. 1999. "Aerosol backscatter fraction and singlescattering albedo: Measured values and uncertainties at a coastal station in the Pacific Northwest." Journal of Geophysical Research 104: 26793-26807.

Bond, TC, TL Anderson, and D Campbell. 2001. "Calibration and intercomparison of filter-based measurements of visible light absorption by aerosols." Aerosol Science and Technology 30: 582-600.

Heintzenberg, J, A Wiedensohler, TM Tuch, DS Covert, P Sheridan, JA Ogren, J Gras, R Nessler, C Kleefeld, N Kalivitis, V Aaltonen, R-T Wilhelm, and M Havlicek. 2006. "Intercomparisons and aerosol calibrations of 12 commercial integrating nephelometers of three manufacturers." Journal of Atmospheric and Oceanic Technology 23(7): 902-914.

Lack, DA, CD Cappa, DS Covert, T Baynard, P Massoli, B Sieru, TS Bates, PK Quinn, ER Lovejoy, and AR Ravishankara. 2008. "Bias in filter-based light absorption measurements due to organic aerosol loading: evidence from ambient measurements." Aerosol Science and Technology 42:1033-1041.

Sheridan, PJ, DJ Delene, and JA Ogren. 2001. "Four years of continuous surface aerosol measurements from the Department of Energy's Atmospheric Radiation Measurement Program Southern Great Plains Cloud and Radiation Testbed site." Journal of Geophysical Research 106(D18):

doi:10.1029/2001JD000785.

Virkkula, A, NC Ahlquist, DS Covert, WP Arnott, PJ Sheridan, PK Quinn, and DJ Coffman. 2005. "Modification, calibration and a field test of an instrument for measuring light absorption by particles." Aerosol Science and Technology 39: 68-83. 


\section{Appendix A}

\section{Aerosol Hygroscopic Growth (fRH) Measurements}

The AOS humidified nephelometer measures the increase in the aerosol scattering coefficient with relative humidity $(\mathrm{RH})$. Figure A.1 shows a diagram of the humidifier setup. The instrument setup consists of two nephelometers in series with a humidifier between them. The "reference" nephelometer measures the dry aerosol scattering coefficients. The sample air moves through a humidifier, which steps the RH from about $40-85 \%$, and the second nephelometer measures the aerosol scattering at the elevated RH. Actual RH values vary with the ambient dew point, sample residence time in the humidifier, water temperature, and humidifier porosity.

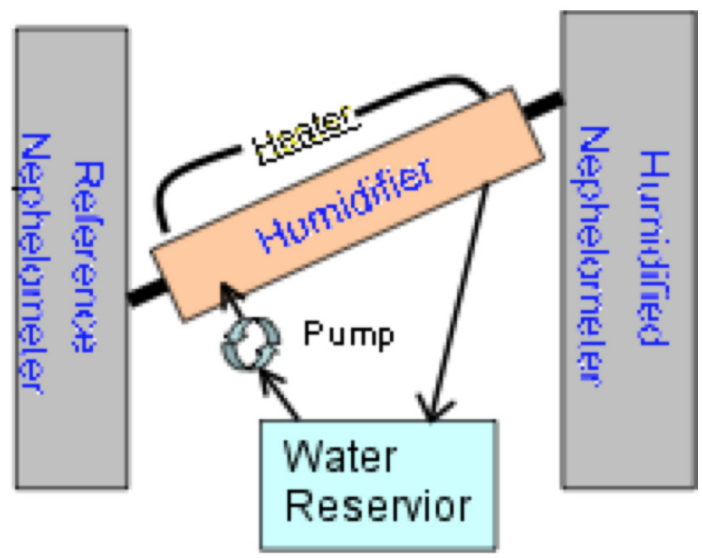

Figure A.1. Simplified diagram of humidified nephelometer instrumentation.

The RH in the humidifier scans from low to high RH and back to low RH on an hourly basis. Figure A.2 below shows the hourly RH signals from the sensors in the system. RH and T sensors are located at the sample inlet to the impactor (sample); after a heater at the entrance to the reference nephelometer (heater); inside the reference nephelometer (ref); inside the humidified nephelometer (wet); and at the output of the humidified nephelometer (S2). The S2 sensor is the control sensor for the humidifier RH. In the fRH VAP, the RH inside the humidified nephelometer is calculated from the calculated dewpoint at the exit of nephelometer and the temperature inside the nephelometer. The internal nephelometer RH sensor is not used in calculations because of its slower response time and higher uncertainty.

The aerosol hygroscopic growth is a measure of the increase in aerosol scattering relative to a dry, "reference" scattering with changes in relative humidity. A common way to quantify this growth is the aerosol hygroscopic growth factor, $\mathrm{fRH}$, which is the ratio of the aerosol scattering coefficient at $85 \% \mathrm{RH}$ to that at $40 \% \mathrm{RH}$.

$$
\mathrm{fRH}=\sigma \operatorname{sp}(85 \%) / \sigma \operatorname{sp}(40 \%)
$$




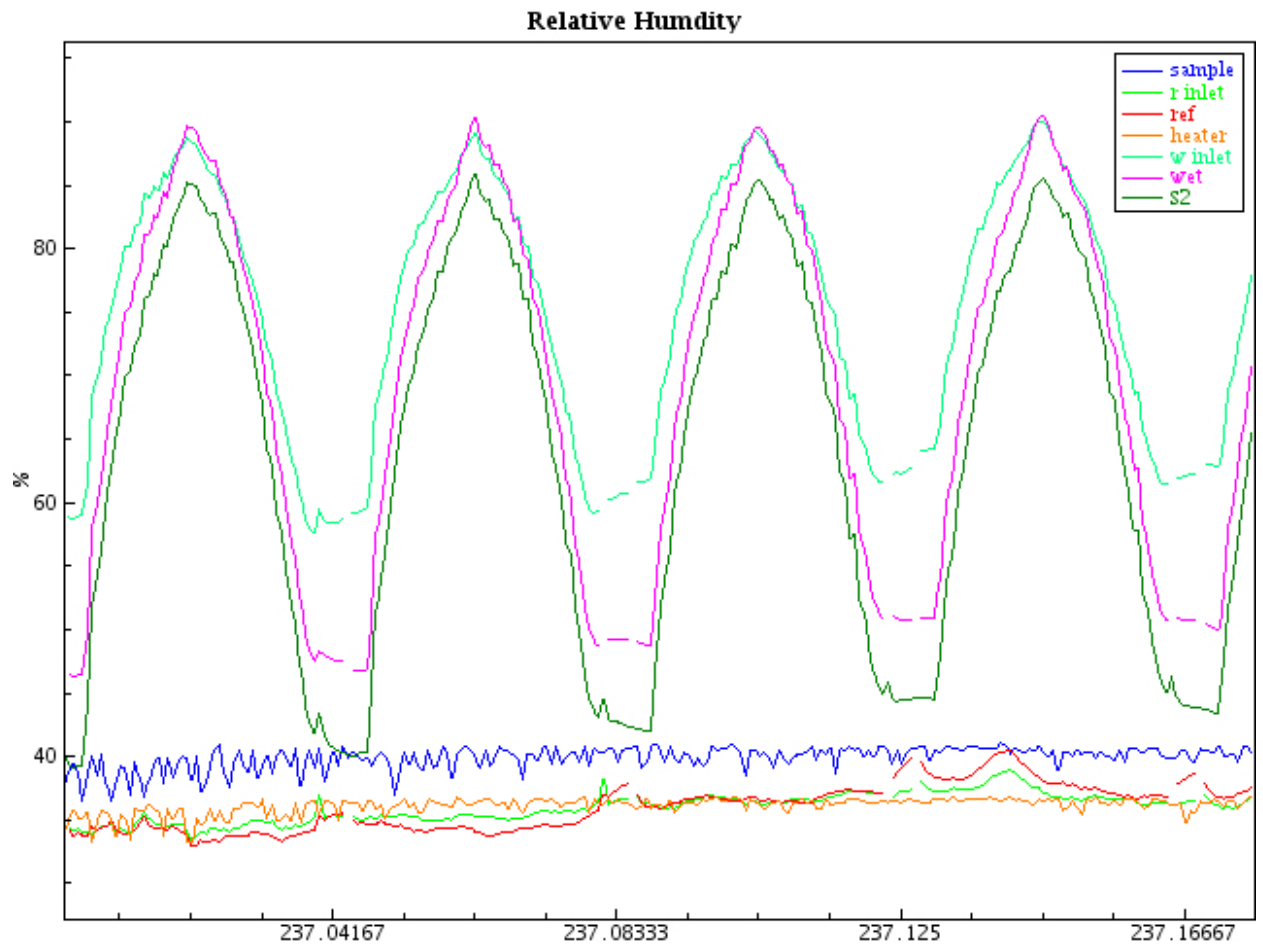

Figure A.2. Plot of relative humidity values versus day of year in 2010 for the AOS system at SGP.

The hygroscopic growth VAP is available in the ARM Data Archive as the xxxcmdlaosfitrhC1.c1 datastream, where $\mathrm{xxx}$ designates the site name (sgp, nsa, or one of the amf sites). The VAP model computes the fit parameters for the aerosol hygroscopic growth from both 2 and 3 parameter empirical fits of the data.

$$
\begin{aligned}
& \sigma \operatorname{sp}(\text { wet }) / \sigma s p(\text { dry })=a\left(1-R H_{w} / 100\right)^{-\gamma} \\
& \sigma s p(\text { wet }) / \sigma s p(\text { dry })=b\left(1+c\left(R H_{w} / 100\right)^{-d}\right.
\end{aligned}
$$

The first 2-parameter fit is discussed by Hanel (1976) and the 3-parameter fit by Kotchenruther et al. (1999). Both models assume equilibrium (metastable) growth of the aerosol scattering with RH such that the humidigraph profile does not display a deliquescent growth profile. For aerosol in a humid environment, this behavior will hold true. Most aerosols are a mixture of metastable and deliquescent particles and will exhibit some deliquescent behavior. A quality check of the hygroscopic fit parameter data is the chi-square fit parameter, which indicates how well the data fit the calculated parameters. Another check of the appropriate use of such fits is the ambient RH or sample inlet RH. The likelihood of the aerosol displaying a deliquescent growth profile increases as the ambient RH declines. The metastable or deliquescent behavior of the aerosol will vary with composition. The "a" and " $b$ " parameters in equations (1) and (2) will vary with aerosol loss in the humidifier, small differences in the instrument calibrations, and zeros. These parameters are not used typically in the calculation of the aerosol scattering at a specific RH. For calculation of the ambient state scattering, $\sigma \operatorname{sp}(\mathrm{amb})$, from the 2-parameter fit, use the following equation. 


$$
\sigma_{s p}(a m b)=\sigma_{s p}(d r y) \frac{\left(1-R H_{a m b} / 100\right)^{-\gamma}}{\left(1-R H_{d r y} / 100\right)^{-\gamma}}
$$

The figures below show humidigraph profiles and a 2-parameter fit of the data from 2010 at SGP.

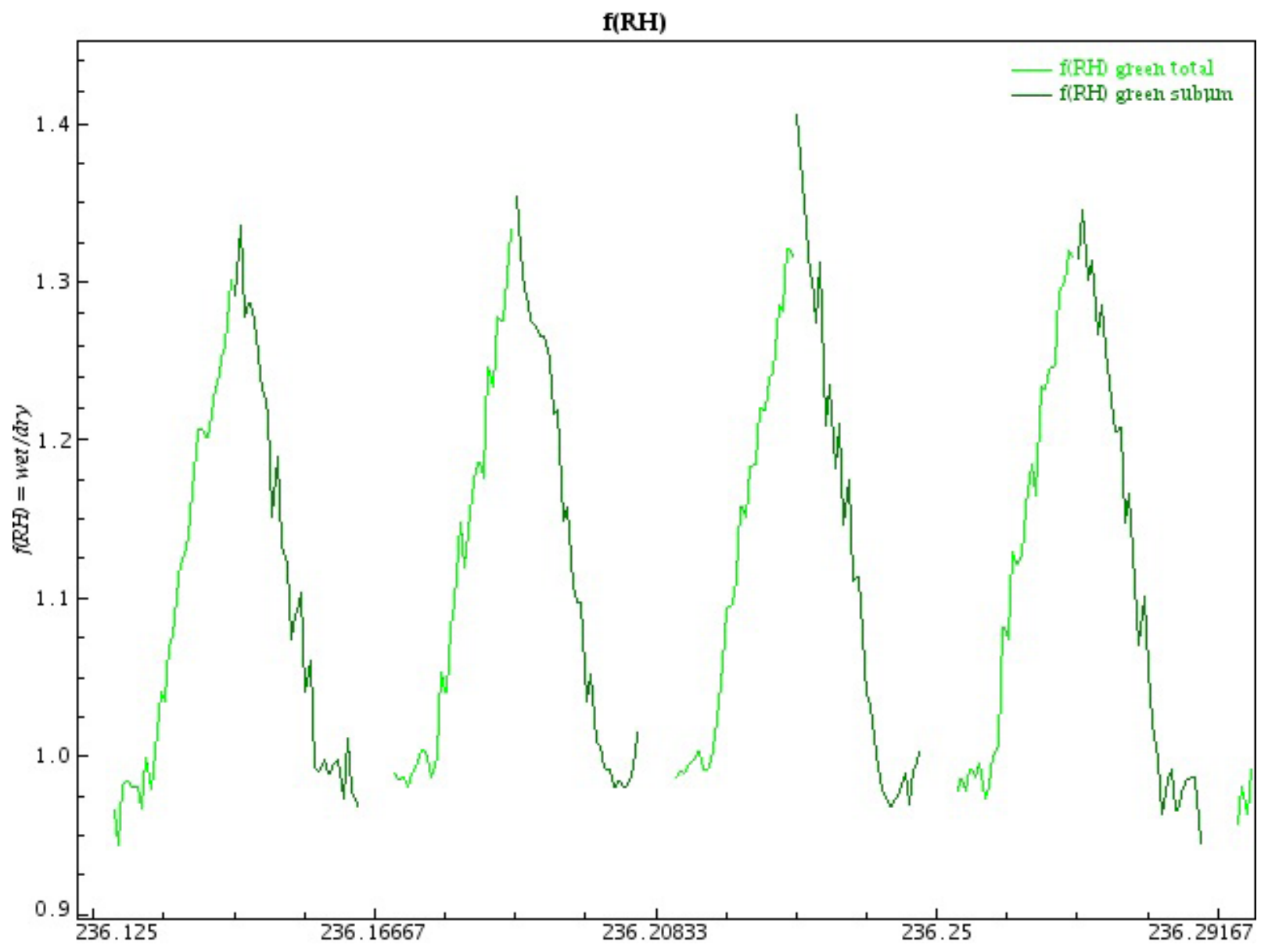

Figure A.3. Raito of $\sigma \operatorname{sp}($ wet)/ $\sigma \operatorname{sp}($ dry) at $550 \mathrm{~nm}$ versus decimal day of year 2010. Four hours of data are shown. The first 30 minutes of each hour is sub-10-micron size aerosol (light green), and the last 30 minutes is submicron size aerosol (dark green). 


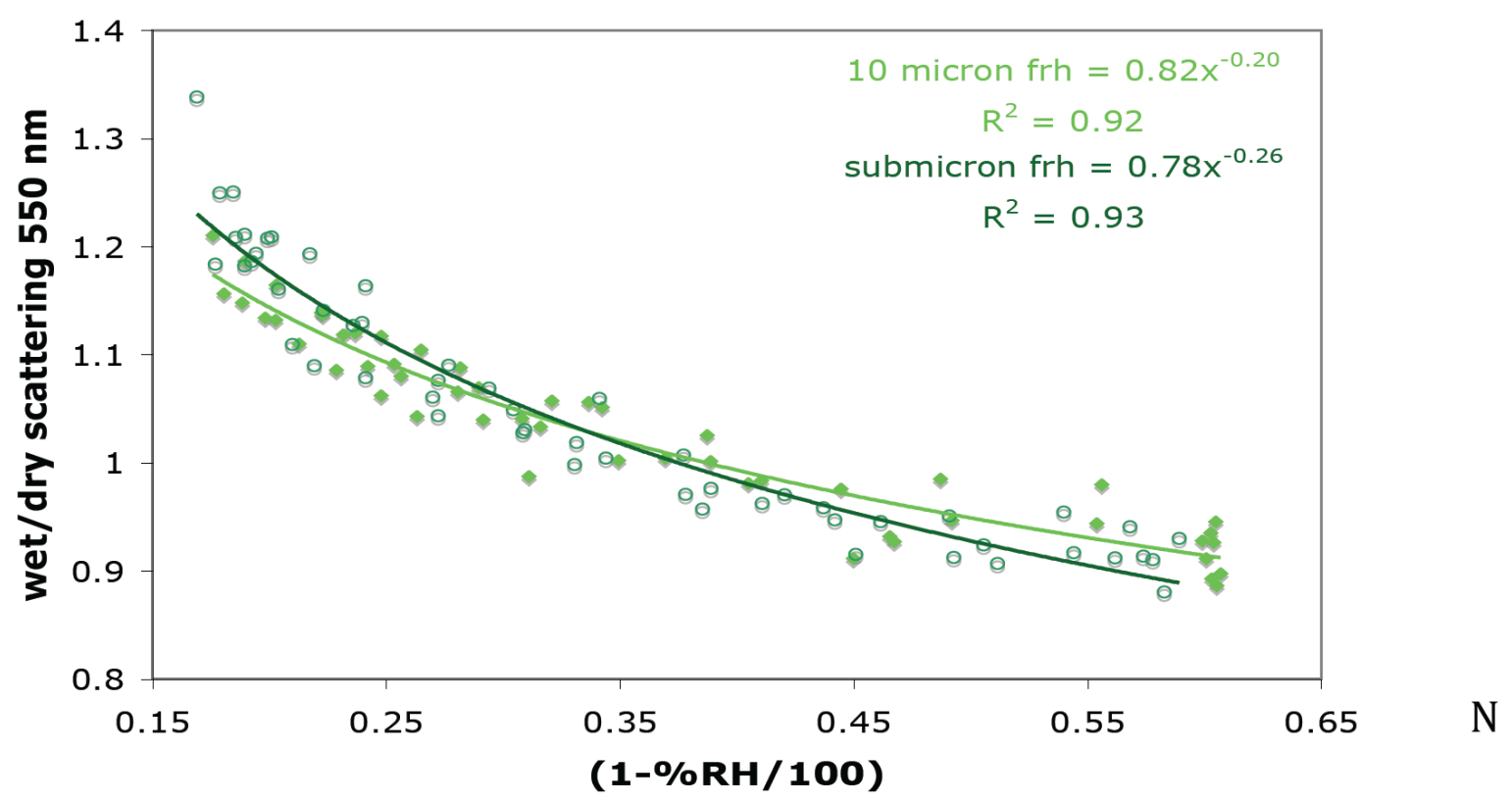

Figure A.4. Ratio of $\sigma \mathrm{sp}($ wet $) / \sigma \mathrm{sp}($ dry) at $550 \mathrm{~nm}$ versus $(1-\% \mathrm{RH} / 100)$. The 2-parameter fit curves are for sub-10-micron (light green) and submicron (dark green) data from day 237 (August 25, 2010) at SGP. Two hours of data are shown with one-minute data integration.

\section{$\underline{\text { References: }}$}

Hanel, G. 1976. "The properties of atmospheric aerosol particles as functions of the relative humidity at thermodynamic equilibrium with the surrounding moist air." Advances in Geophysics 19: 73-188.

Kotchenruther, RA, PV Hobbs, and DA Hegg. 1999. "Humidification factors of atmospheric aerosols off the mid-Atlantic coast of the United States." Journal of Geophysical Research 104: 2239-2251.

$\underline{\text { ARM xxxcmdlaosfitrhC1.c1 netcdf file formats and operation dates }}$

There are 4-5 parameters for each fit:

1. Calculated ratio of wet/dry scattering coefficients at $85 / 40 \mathrm{RH}$

2. $\mathrm{fRH} \chi^{2}$ Pearson's goodness of fit coefficient

3-5. fRH fit parameters.

There are 18 fits:

- Red, green, and blue wavelengths

- Sub-um, sub-10-um size aerosol

- Total and hemispheric back scattering coefficients

- 2 and 3 parameter fits

- Only the 2-parameter fits exist for the 6 backscattering values

- 2 and 3 parameter fits exist for the 6 total scattering values. 


\section{Fit boundary conditions:}

All of the fits have between 14-27 one-minute data points. Humidigraph scans with less than 14 points have a missing value codes for their fit parameters.

The fits are truncated to start at a minimum $\mathrm{RH}$ of $40 \%$. Below this $\% \mathrm{RH}$, the ratio of wet/dry scattering tends to be flat with changes in $\%$ RH. The fit quality decreases if data below $40 \%$ are included in the fit, as the fit assumes an increasing scattering ratio with $\mathrm{RH}$.

The initial \% RH of the humidigraph scan in the wet nephelometer has a maximum value of $65 \%$. Fit parameters with initial \%RH values above $65 \%$ in the wet nephelometer are replaced with missing value codes.

Fit parameters with $\mathrm{fRH}(85 \% / 40 \%)$ fit parameters above 5.0 are replaced with missing value codes.

Operations dates of $f R H$ measurements.

- SGP: January 1999-present

- NSA: September 2006-present

- PYE: July-September 2005

- NIM: December 2005-December 2006

- FKB: May-December 2007

- HFE: May-December 2008

- GRW: May 2009-December 2010

- PGH: May 2011-April 2012.

The netcdf file format is located on the ARM website at https://engineering.arm.gov/tool/dod/showdod.php?Inst=cmdlaosfitrh\&View=dev.

The basic format is given below. "X" refers to either a blue (B), green (G), or red (R) nephelometer wavelength, and * refers to either 10- or 1-um-size aerosol. The files give hourly fit values for either the sub-um or sub-10-um size aerosol. The one-minute data that went into the fits are located in the xxxaosC1.a1 data files, where xxx is the station identifier. All fits were performed using a Levenburg--Marquardt, nonlinear, least-squares fitting method.

\section{File variables:}

int base time ;

double time_offset(time);

double time(time);

fRH_85by40_3param_*_Xum:long_name = "X wavelength, fitted value of $\mathrm{f}(\mathrm{RH})$ for $85 / 40$, three parameter fit, *um" ;

fRH_3param_chi_*_Xum:long_name $=$ "X wavelength, goodness of fit parameter, three parameter fit, *um" ; 
$\mathrm{fRH}$ _Bs_X_um_min:long_name $=$ "X wavelength, minimum light scattering coefficient for wavelength reported by STP, *um" ;

fRH_RH_Dry_*um_min:long_name = "X wavelength, minimum dry relative humidity used in curve fit, *um" ;

fRH_RH_Dry_*um_max:long_name = "X wavelength, maximum dry relative humidity used in curve fit, *um" ;

fRH_RH_Wet_um_min:long_name $=$ "X wavelength, minimum wet relative humidity used in curve fit, *um" ;

fRH_RH_Wet_*um_max:long_name = "X wavelength, maximum wet relative humidity used in curve fit, *um" ;

fRH_3param_p1_X_*um:long_name = "X wavelength, three parameter curve fit, parameter 1, *um" ;

$\mathrm{fRH}$ _3param_p2_X_*um:long_name $=$ "X wavelength, three parameter curve fit, parameter 2, *um" ;

fRH_3param_p3_X_*um:long_name $=$ "X wavelength, three parameter curve fit, parameter 3, *um" ;

$\mathrm{fRH}$ _85by40_2param_X_*um:long_name $=$ "X wavelength, fitted value of $\mathrm{f}(\mathrm{RH})$ for $85 / 40$, two parameter fit, *um" ;

fRH_2param_chi_X_*um:long_name = "X wavelength, Goodness of fit parameter, two parameter fit, *um" ;

fRH_2param_p1_X_*um:long_name = "X wavelength, two parameter curve fit, parameter 1, 10um" ;

$\mathrm{fRH}$ _2param_p2_X_*um:long_name $=$ "X wavelength, two parameter curve fit, parameter 2, *um" ;

$\mathrm{fRH}$ _85by40_Bbs_X_10um:long_name = "X wavelength, fitted value of $\mathrm{f}(\mathrm{RH})$ for 85/40 for bbsp, *um" ;

$\mathrm{fRH}$ _Bbs_X_*um:long_name $=$ "X wavelength, fitted value of $\mathrm{f}(\mathrm{RH})$ for bbsp, *um";

fRH_Bbs_chi_X_*um:long_name $=$ "X wavelength, goodness of fit, bbsp fit, *um" ;

fRH_Bbs_p1_X_*um:long_name = "X wavelength, parameter 1 for bbsp curve fit, *um"

fRH_Bbs_p2_X_*um:long_name = "X wavelength, parameter 2 for bbsp curve fit, *um" 


\section{Appendix B}

\section{Cloud Condensation Nuclei (CNN) Measurements}

Cloud condensation nuclei $(\mathrm{CCN})$ are particles that are capable of activating to form cloud droplets at a given percent super saturation (\%ss). According to the Köhler equation, the vapor pressure or \%ss above an aqueous drop will vary with the drop surface tension or size and the solute concentration or chemical composition. The AOS CCN measurements report the CCN concentration over a range of \%ss values. The SGP site has complementary aerosol size, composition, and gRH measurements that can be used to predict CCN. CCN measurements are available from SGP, NSA, PYE, NIM, FKB, HFE, and GRW sites as well as future AMF2 and Darwin sites.

The CCN data are from ground-based and aircraft IOP in situ measurements. The surface sites measure the $\mathrm{CCN}$ concentration at several super saturations using a DMT single-column CCN counter (Roberts and Nenes 2005). The percent super saturation of the instrument is stepped through 7 intervals every 30 minutes with 5 minutes at each setting in a pyramid profile. The \%ss in the CCN datastream is calculated using a heat transfer and fluid dynamics model flow model (Lance et al. 2006). The model uses the calibrated temperature, pressure, and flows in the instrument to calculate the \%ss. Small variations in the $\%$ ss will arise from changes in the column thermal properties in the instrument. Rose et al. (2008) discusses the model and salt calibration calculations of the instrument \%ss and uncertainty associated with thermal properties. The CCN instrument is serviced and calibrated at the beginning of each deployment for the mobile facility and annually for the SGP site. The CCN \%ss stepping scheme and two hours of data appear in Figure B.1 below.

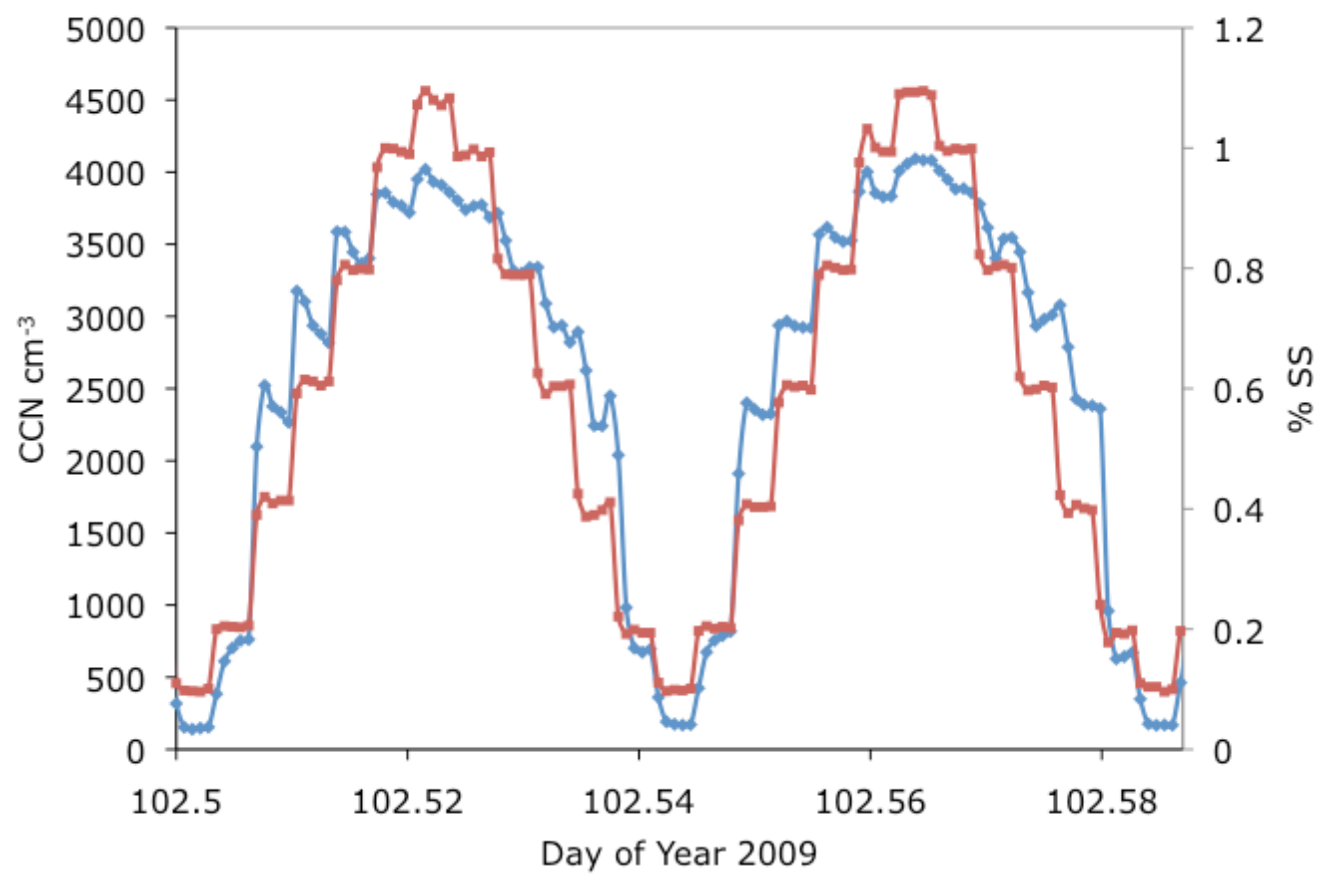

Figure B.1. Stepping scheme of \%SS (red) and typical CCN number concentration (blue) on April 12, 2009, at SGP. 
The first minute after a change in \%ss, the CCN temperatures are not stable, and the \%ss values usually overshoot the set point value. For this reason, the first minute of every \%ss setting is disregarded, and only the last four minutes are averaged together. Rose et al. 2008 note a higher deviation of the \%ss value from the calibration fit line at low \%ss values. Care should be taken when using \%ss values below 0.15 , as the error in the calibrations is much higher than at higher \%ss values. At very high particle concentrations, the instrument becomes water-limited, and a high fraction of the particles do not activate to droplets. Lathem and Nenes (2011) present a correction scheme for the \%ss decrease under conditions of high CN concentrations greater than $5000 \mathrm{~cm}^{-3}$.

The AOS CCN datastream stnaoscenC1.a1.YYYYMMDD.* contains the instrument raw data. "stn" refers to the station name, e.g. SGP. The data file has one-minute averaged data. The \%ss value changes every 5 minutes. The differential temperature across the column and \%ss value during the first minute of each \%ss change is unstable and should not be used. There are two reported \%ss values in the file:

CCN_ss_set(time) is the \%ss value reported by the instrument, and CCN_ss_calc(time) is the \%ss value calculated from the Lance et al. 2006 model. The lowest size bin of the $\overline{\mathrm{OPC}}$ detector is usually set to 1 micron. The instrument will count super-micron aerosol particles as CCN. This over-counting of CCN is a problem during times with unusually high number concentrations of large particles such as dust or sea salt. During known periods with high super micron particle concentrations, the lowest size bins can be eliminated from the total $\mathrm{CCN}$ number concentration, especially at the lowest \%ss value. One-minute, mentor-edited CCN data is available in the stnaosX1.a1.YYYYMMDD.* datastream as the N_CCN_1 (time) parameter.

The CCN raw data stream netcdf header file follows.

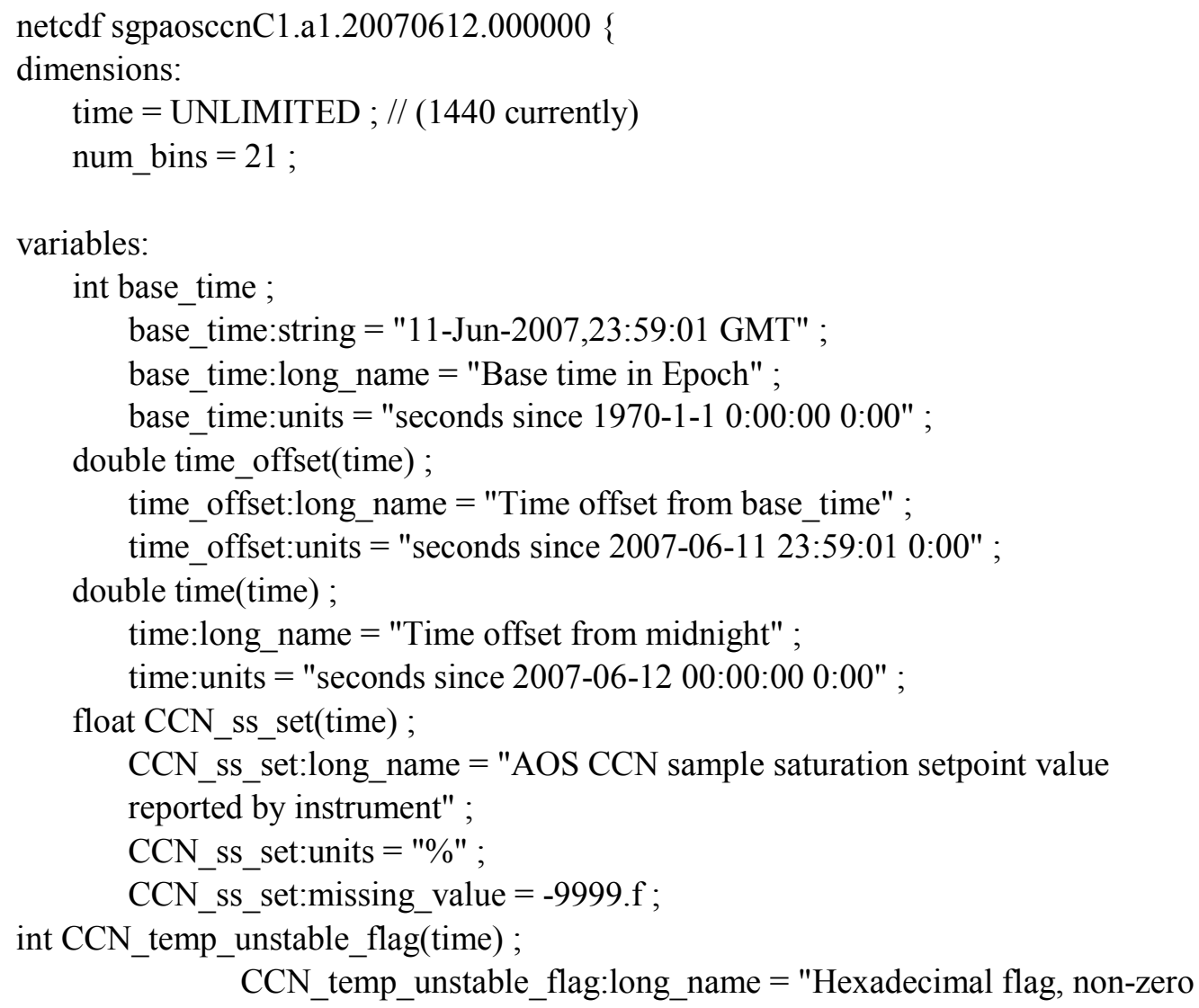


value means instrument is not operating stably" ;

CCN_temp_unstable_flag:units = "unitless" ;

CCN_temp_unstable_flag:missing_value $=-9999$;

CCN_temp_unstable_flag:bit_1 = "(0x02) set by CPD, based on standard deviation of column temperature difference (threshold exceeded)" ;

float CCN_T_TEC1(time);

CCN_T_TEC1:long_name $=$ "AOS CCN temperature at top of column" ;

CCN_T_TEC1:units $=$ "degrees $C "$;

CCN_T_TEC1:missing_value $=$-9999.f ;

float CCN_T_TEC2(time);

CCN_T_TEC2:long_name $=$ "AOS CCN temperature at middle of column" ;

CCN_T_TEC2:units $=$ "degrees C" ;

CCN_T_TEC2:missing_value $=-9999 . f$;

float CCN_T_TEC3(time) ;

CCN_T_TEC3:long_name $=$ "AOS CCN temperature at bottom of column" ;

CCN_T_TEC3:units $=$ "degrees C" ;

CCN_T_TEC3:missing_value $=$-9999.f ;

float CCN_T_sample(time);

CCN_T_sample:long_name $=$ "AOS CCN temperature of sample air entering the column";

CCN_T_sample:units = "degrees C" ;

CCN_T_sample:missing_value $=$-9999.f ;

float CCN_T_inlet(time) ;

CCN_T_inlet:long_name $=$ "AOS CCN temperature of sample air at entrance to instrument" ;

CCN_T_inlet:units $=$ "degrees $\mathrm{C} "$;

CCN_T_inlet:missing_value $=$-9999.f ;

float CCN_T_OPC(time) ;

CCN_T_OPC:long_name $=$ "AOS CCN temperature of the optical particle counter" ;

CCN_T_OPC:units = "degrees C" ;

CCN_T_OPC:missing_value $=$-9999.f ;

float CCN_T_nafion(time) ;

CCN_T_nafion:long_name $=$ "AOS CCN temperature of the nafion humidifier" ;

CCN_T_nafion:units $=$ "degrees $\mathrm{C} "$;

CCN_T_nafion:missing_value $=$-9999.f ;

float CCN_dT_TEC3_TEC1_StdDev(time);

CCN_dT_TEC3_TEC1_StdDev:long_name $=$ "AOS CCN standard deviation of difference (CCN_T_TEC1 - CCN_T_TEC3)" ;

CCN_dT_TEC3_TEC1_StdDev:units = "degrees C" ;

26

CCN_dT_TEC3_TEC1_StdDev:missing_value = -9999.f ; 
float CCN_Q_sample(time) ;

CCN_Q_sample:long_name $=$ "AOS CCN volumetric flowrate of sample air" ;

CCN_Q_sample:units $=" \mathrm{~cm}^{\wedge} 3 /$ minute" ;

CCN_Q_sample:missing_value $=$-9999.f ;

float CCN_Q_sheath(time);

CCN_Q_sheath:long_name $=$ "AOS CCN volumetric flowrate of sheath air" ;

CCN_Q_sheath:units $=$ "cm^3/minute" ;

CCN_Q_sheath:missing_value $=$-9999.f;

float CCN_P_sample(time) ;

CCN_P_sample:long_name = "AOS CCN sample pressure" ;

CCN_P_sample:units $=" \mathrm{hPa} "$;

CCN_P_sample:missing_value $=$-9999.f ;

float CCN_laser_current(time);

CCN_laser_current:long_name = "AOS CCN OPC laser current" ;

$\mathrm{CCN}$ _laser_current:units = "mA" ;

CCN_laser_current:missing_value $=$-9999.f ;

float N_CCN(time) ;

N_CCN:long_name $=$ "AOS number concentration of $\mathrm{CCN}$ " ;

N_CCN:units $=" 1 / \mathrm{cm}^{\wedge} 3 "$;

N_CCN:missing_value $=-9999 . f$;

int N_CCN_bin_number(time);

N_CCN_bin_number:long_name $=$ "AOS bin number of lowest channel

of OPC include in summation of N_CCN" ;

N_CCN_bin_number:units = "unitless" ;

N_CCN_bin_number:missing_value $=-9999$;

float N_CCN_dN(time, num_bins) ;

N_CCN_dN:long_name $=$ "AOS CCN number concentration by bin " ;

N_CCN_dN:units = "unitless" ;

N_CCN_dN:missing_value $=$-9999.f ;

N_CCN_dN:comment1 = "Each bin contains a droplet count, based on droplet size" ;

N_CCN_dN:comment2 $=$ "Bin droplet size (top of each bin) are

$0.75 \mathrm{um}, 1.0 \mathrm{um}, 1.5 \mathrm{um}, 2.0 \mathrm{um}, 2.5 \mathrm{um}$... to $10 \mathrm{um}$ in $0.5 \mathrm{um}$ increments" ;

float CCN_ss_calc(time) ;

CCN_ss_calc:long_name $=$ "AOS CCN sample supersaturation

calculated by model)" ;

CCN_ss_calc:units $=" \% "$;

CCN_ss_calc:missing_value $=$-9999.f ;

CCN_ss_calc:model_documentation1 = "Roberts, G. C. and Nenes, A. (2005)" ;

CCN_ss_calc:model_documentation2 = "A continuous-flow streamwise thermal-gradient $\mathrm{CC} \overline{\mathrm{N}}$ chamber for atmospheric measurements." ;

CCN_ss_calc:model_documentation3 = "Aerosol Sci. Tech., 39, 206$221 "$; 
27

CCN_ss_calc:model_documentation4 = "Lance, S., Medina, J., Smith, J. N. and Nenes, A. (2006)" ;

CCN_ss_calc:model_documentation5 = "Mapping the operation of the DMT continuous flow CCN counter" ;

CCN_ss_calc:model_documentation6="Aerosol Sci. Tech., 2006" ;

float CCN_UpperSizeLimit(num_bins);

CCN_UpperSizeLimit:long_name = "Size of upper limit of each CCN bin" ;

CCN_UpperSizeLimit:units = "um" ;

CCN_UpperSizeLimit:missing_value = -9999.f ;

float CCN_FirstStageMonitorVoltage(time);

CCN_FirstStageMonitorVoltage:long_name $=$ "First stage monitor voltage" ;

CCN_FirstStageMonitorVoltage:units = "V (DC)" ;

CCN_FirstStageMonitorVoltage:missing_value $=$-9999.f ;

float CCN_Temperature_Gradient(time);

CCN_Temperature_Gradient:long_name $=$ "CCN temperature gradient" ;

CCN_Temperature_Gradient:units $=$ "C" ;

CCN_Temperature_Gradient:missing_value $=$-9999.f ;

float CCN_ProportionalValveVoltage(time) ;

CCN_ProportionalValveVoltage:long_name $=$ "CCN Propotional

valve voltage" ;

CCN_ProportionalValveVoltage:units = "V" ;

CCN_ProportionalValveVoltage:missing_value $=$-9999.f ;

float lat ;

lat:long_name $=$ "north latitude" ;

lat:units = "degrees" ;

lat:valid_min $=-90 . f$;

lat:valid $\max =90 . \mathrm{f}$;

float lon ;

lon:long_name $=$ "east longitude" ;

lon:units $=$ "degrees" ;

lon:valid_min $=-180 . f$;

lon:valid_max $=180 . f$;

float alt ;

0alt:long_name $=$ "altitude" ; 


\section{$\underline{\text { References: }}$}

Lance, S, J Medina, JN Smith, and A Nenes. 2006. "Mapping the operation of the DMT continuous flow CCN counter." Aerosol Science and Technology 40(4): 242-254.

Lathem, TL, and A Nenes. 2011. "Water vapor depletion in the DMT continuous flow CCN chamber: effects on supersaturation and droplet growth." Aerosol Science and Technology, in press.

Roberts, G, and A Nenes. 2005. "A continuous-flow streamwise thermal- gradient CCN chamber for atmospheric measurements." Aerosol Science and Technology 39(3): 206-221.

Rose, D, SS Gunthe, E Mikhailov, GP Frank, U Dusek, MO Andreae, and U Poschl. 2008. "Calibration and measurement uncertainties of a continuous-flow cloud condensation nuclei counter (DMT-CCNC): CCN activation of ammonium sulfate and sodium chloride aerosol particles in theory and experiment." Atmospheric Chemistry and Physics 8: 1153-1179. 


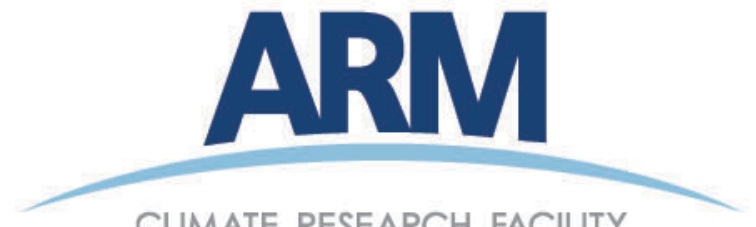

CLIMATE RESEARCH FACILITY

www.arm.gov

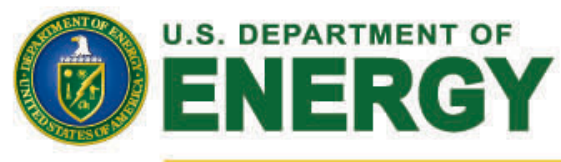

Office of Science 